\title{
A novel STATCOM control scheme for the coordination with OLTC on voltage regulation
}

\author{
San-Yi Lee ${ }^{\mathrm{a}^{*}}$, Yung-Sung Chuang ${ }^{\mathrm{b}}$, Jun-Wei Lai ${ }^{\mathrm{a}}$ \\ ${ }^{a}$ Department of Electrical Engineering, Taipei Chengshih University of Science and Technology, Beitou, Taipei 11202, Taiwan \\ ${ }^{b}$ Department of Electrical Engineering, Minghsin University of Science and Technology, Xinfeng, Hsinchu 30401, Taiwan
}

\begin{abstract}
When an static synchronous compensator (STATCOM) is installed with an on-load tap-changer (OLTC), in general, a coordinated voltage control scheme, where the STATCOM responses for transient voltage variation and the OLTC for long-term voltage variation, is required to reserve the operating margin of STATCOM for emergency conditions, and reduce the operating losses. In this paper, an independent control scheme for the voltage regulation of STATCOM is proposed. The proposed control scheme is based on the feedback of processed line voltages to the reference voltage input of STATCOM to reduce the compensation output when the terminal voltage is in its steady state, but still can provide high compensation output when there is an abnormal low voltage contingency in the upstream. It's shown that the proposed STATCOM control scheme can coordinate well with OLTC in all simulated scenarios.
\end{abstract}

Keywords: Voltage regulation, static synchronous compensator, on-load tap-changer

\section{Introduction}

Due to the continuous advancement of power electronics, static synchronous compensator (STATCOM) has gradually become one of the major options for the improvement of power system transient stability and dynamic voltage regulation because of its high speed ability of controlling the output of reactive power. On the other hand, in order to provide customers a stable and near-rated voltage, power utilities utilize on-load tap-changer (OLTC) to adjust the secondary voltage by changing the transformer turn ratio, which in reality is achieved by automatic moving the tap position based on the detected bus voltage. Because tap moving is mechanical action, the response time of OLTC is much larger than that of STATCOM. Fig. 1 shows the basic structures and control mechanisms of STATCOM and OLTC.

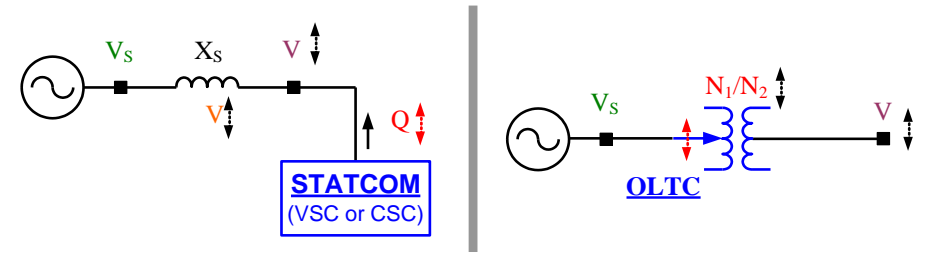

Fig. 1. Basic structures and control mechanisms of STATCOM and OLTC.

In order to reduce the operating cost of STATCOM and provide largest capacity in the transient voltage events, it's preferred that the STATCOM only responses to the transient voltage changes. That is, the long term voltage regulation is designed to belong to the duty of OLTC for the benefit of reducing the

* Manuscript received May 16, 2013; revised July 29, 2013.

Corresponding author. Tel.: +886-2-28943356 ext 411; E-mail address: sylee@tpcu.edu.tw. 
steady state output of STATCOM. Therefore, when both STATCOM and OLTC are used to control the same bus voltage, a coordination scheme between these two devices is needed to get good performances about voltage regulation, tap change frequency, and operating losses [1-2]. For many circumstances, the installation date of the STATCOM is a long time after that of the OLTC, so the coordination strategies include two types, one is independent control type and the other is STATCOM/OLTC interconnected control type. The STATCOM/OLTC interconnected control type needs to modify the already existing OLTC control system, hence some utilities prefer the independent control type.

Fujii [3] describes the independent regulator of an in-service 80MVA STATCOM in Japan, which adopts a droop voltage control curve with dual slopes. In [4], even though the STATCOM and OLTC share the same control system, its essence is an independent control scheme, wherein the detected bus voltage is sent to the STATCOM directly, but passed through a LPF (Low Pass Filter) before sent to the OLTC. For STATCOM/OLTC interconnected control type, both Khederzadeh [5] and Paserba [6] propose the method of using the output of STATCOM to bias the voltage errors seen by the OLTC to force the moving of tap changer to release the output capacity of STATCOM. In [7], an artificial neural network (ANN)-based controller with load P, load Q, tap position, and STATCOM output as its inputs is proposed as the tap controller of OLTC.

For STATCOM/OLTC interconnected control type, the controller of OLTC receives the amplitude of STATCOM output continuously, so it can react and reduce the output of the STATCOM quickly, however, it needs to change the OLTC control hardware. Hence, for a newly installed STATCOM, an independent control method is a worth option. In this paper, a novel independent control method is proposed. The proposed control scheme is based on the feedback of processed primary and secondary voltages to the reference voltage input of STATCOM to reduce the compensation output when the terminal voltage is in its steady state, but still can provide high compensation output when there is an abnormal low voltage contingency in the upstream. The performance of the proposed control method and its comparison with the basic STATCOM control method are validated and analyzed with the simulations by MATLAB/SIMULINK.

\section{Voltage Regulation Principles of STATCOM}

Fig. 2 (a) shows the effects of droop curve slope on the STATCOM output. Clearly, the output of STATCOM is inversely proportional to the slope of droop curve. Fujii [3] utilizes this principle to design a dual-slope droop curve for the coordination of STATCOM and OLTC. Fig. 2 (b) shows the effect of reference voltage of droop curve on the STATCOM output which is the principle utilized by the proposed control scheme. As can be seen from Fig. 2 (b), when the $V_{r e f}$, the reference voltage of droop control curve, is adjusted to equal to the Thevenin equivalent voltage $\left(V_{S}\right)$, the compensation output of STATCOM will be zero. Hence, when the $V_{\text {ref }}$ is the low-pass-filtered signal of the bus voltage, the output capacity of STATCOM will be released in the steady-state.

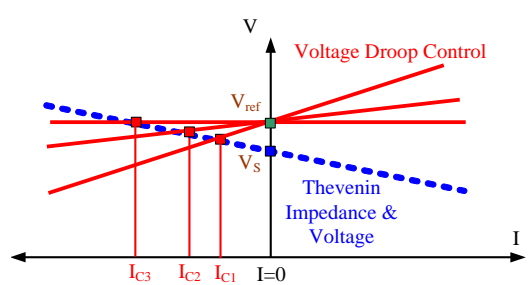

(a)

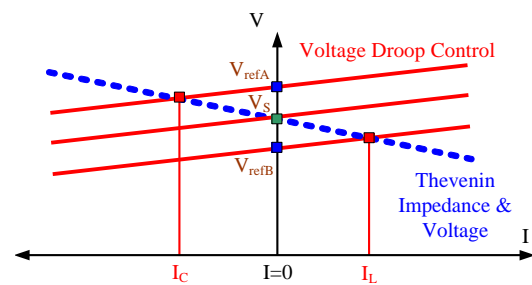

(b)

Fig. 2. Effects of droop control curve on STATCOM output: (a) effect of slope and (b) effect of reference voltage.

\section{Proposed Control Scheme}

Fig. 3 shows the scheme of a basic STATCOM controller. If the measured bus voltage ( $V_{S 1}$ in Fig. 3$)$ is larger than the preset reference voltage ( $V_{\text {ref }}$ in Fig. 3), the STATCOM will provide inductive reactive 
power to reduce the bus voltage. In the contrary, if the measured bus voltage ( $V_{S 2}$ in Fig. 3 ) is smaller than the preset reference voltage, the STATCOM will provide capacitive reactive power to increase the bus voltage. That is, the STATCOM output is determined definitely by the amplitude of bus voltage which is similar to the control scheme of OLTC. Because the STATCOM response is faster than that of OLTC, the OLTC will move the tap only when the compensation from STATCOM is not enough to reduce the deviation of bus voltage within an OLTC operating step.

Fig. 4 shows the scheme of the proposed independent controller which using the STATCOM $V_{\text {ref }}$ to regulate its output as the mechanism illustrated in Fig. 2 (b). The main feature of this controller is that both the primary and secondary voltages of the transformer are feedback for the STATCOM reference voltage. The secondary voltage is filtered with a LPF before input to the STATCOM $V_{r e f}$. Because the transient portion of the bus voltage will not pass through the filter, there is difference between $V_{r e f}$ and $V_{i n}$, the STATCOM will provide reactive current to compensate the rapid voltage variation. In steady-state, the bus voltage will pass through the LPF, so there is no difference between the $V_{\text {ref }}$ and $V_{\text {in }}$, the STATCOM will not provide compensation current, hence can reduce the operating losses and provide higher compensation capacity for a transient voltage event than a STATCOM which has high steady state output.

In the feedback path of the proposed controller, the primary voltage (in per unit) is first subtracted with 1 per unit. If the deviation of primary voltage from the 1 per unit is larger than the particular value set by the Dead Zone Block shown in Fig. 4, there is non-zero value at the output of Dead Zone Block; that is the STATCOM $V_{\text {ref }}$ will be effect by the primary side voltage. If the primary voltage is higher than 1 per unit, the primary voltage feedback value will be positive which will push the output of STATCOM towards capacitive direction to provide voltage support to the primary side voltage contingency, even the secondary voltage is in a steady state after the primary side voltage contingency.
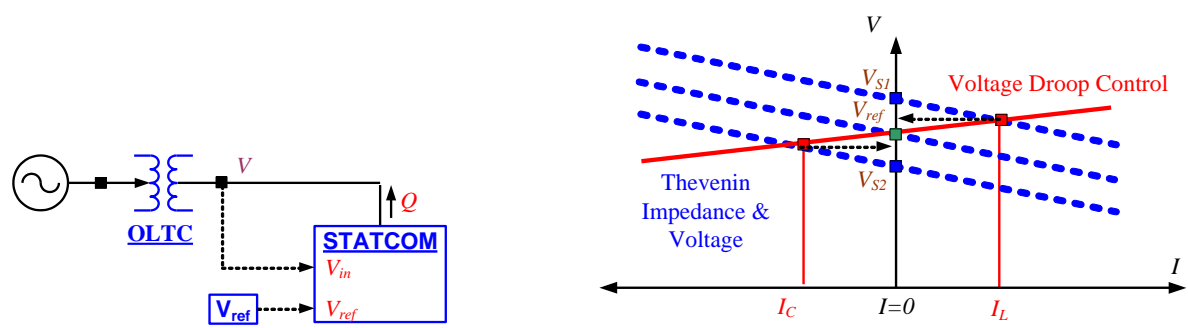

Fig. 3. Basic control scheme.

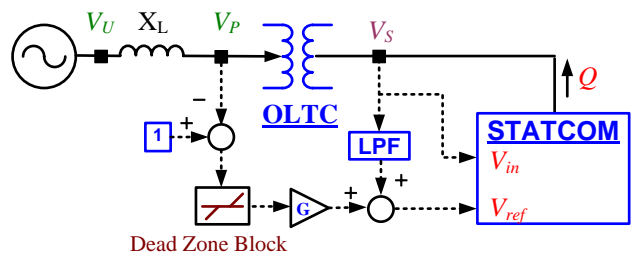

Fig. 4. Proposed control scheme.

\section{Simulation Scenarios}

In order to verify the validation of the proposed independent controller, and compare with basic STATCOM controller, Matlab/Simulink is utilized to carry out the simulations. Fig. 5 shows the simulated sample system built by Matlab/Simulink (control system is removed to simplify the figure), the system parameters are as follows:

- Line 1 and Line 2: $2500 \mathrm{MVAsc}, X / R=10$

- Transformer: $161 / 22.8 \mathrm{kV}, 60 \mathrm{MVA}, Z=17 \%, X / R=25$

- OLTC: step $\Delta V=1.25 \%$, position range $= \pm 8$, dead band $= \pm 1.25 \%$, delay time $=5 \mathrm{sec}$. 


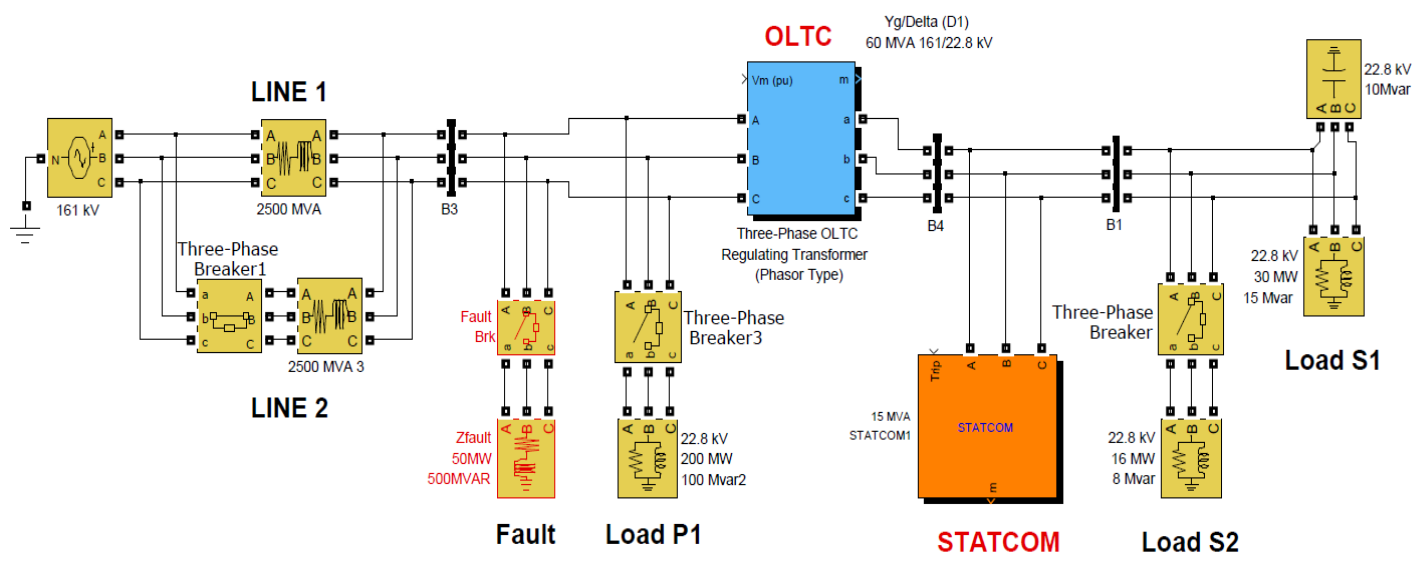

Fig. 5. Simulated sample system in Matlab/Simulink.

- STATCOM: 15 MVar, droop slope $=3 \%$

- Fault: fault capacity $50 \mathrm{MW}, 500 \mathrm{MVar}$

- Load P1 (161 kV): 200 MW, 100 MVar

- Load S1 (22.8 kV): $30 \mathrm{MW}$, inductor=15 MVar, capacitor= $-10 \mathrm{MVar}$

- Load S2 (22.8 kV): $16 \mathrm{MW}, 8 \mathrm{MVar}$

The implementation of the proposed control scheme in Matlab/Simulink is shown in Fig. 6, the controller parameters are as follows:

- Low pass filter (LPF): cutoff frequency $=0.005 \mathrm{~Hz}$, damping factor $=0.707$

- Dead zone block: dead zone -0.04 0.04 p.u.

- Gain: 3

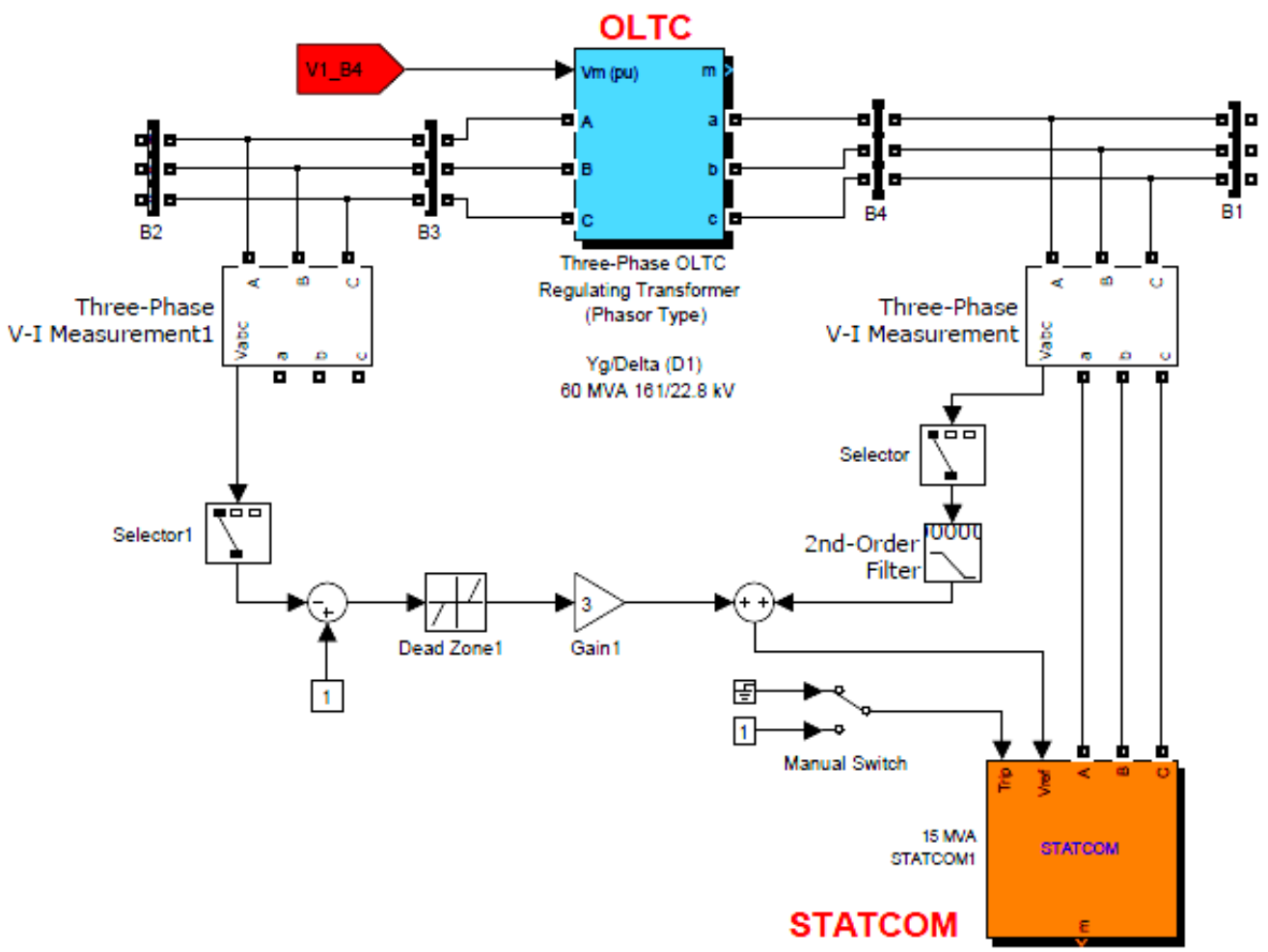

Fig. 6. Proposed independent control scheme in Matlab/Simulink. 
Three scenarios are designed to test the performance of the proposed control scheme, they are:

- Scenario 1: a load variation at $22.8 \mathrm{kV}$ side and a three-phase fault at $161 \mathrm{kV}$ side.

O The fixed load: load $\mathrm{S} 1$.

The switching load: load S2, switching-on at the 50th second.

Fault: occurring at the 150th second.

- Scenario 2: a load variation at $161 \mathrm{kV}$ side.

The fixed load: load S1.

The switching load: load P1, switching-on at the 50th second.

- Scenario 3: a transmission line tripping at $161 \mathrm{kV}$ side.

The fixed load: load S1 and load P1.

$\bigcirc$ The tripping line: line 1, tripping at the 50th second.

\section{Copyright}

For every scenario, three cases are simulated, which include,

- Case 1: without STATCOM,

- Case 2: STATCOM with the basic control scheme, and

- Case 3: STATCOM with the proposed control scheme.

\subsection{Scenario 1: A load variation at $22.8 \mathrm{kV}$ side and a three-phase fault at $161 \mathrm{kV}$ side}

Fig. 7 shows the simulation results of scenario 1 for the abovementioned 3 cases. As can be seen in Fig. 7 (a), after the compensation for the load switching at the 50th second, the proposed controller (case 3) gradually decreases the STATCOM output. On the contrary, the basic controller keeps the STATCOM compensation capacity constant, which means a larger STATCOM operation loss than the proposed controller. Fig. 7 (b) shows that the switching-on of load S2 results in 2 OLTC tap changes for both case 1 and case 3, where case 3 has a longer time distance between the 2 tap changes than that of case 1 . Without a STATCOM, the OLTC in case 1 will continue to moving its tap every 5 seconds until the bus voltage is within the dead band of OLTC regulator. For case 2, the keeping compensation from the noncoordinated STATCOM makes the OLTC inactive. For the fault occurring at 150th second, even thought there is an apparent voltage drop in all three cases, no tap moving occurs because of its short duration. In Fig. 7 (c), with a STATCOM, both case 2 and case 3 have a better secondary bus voltage profile than case 1 at the time instant after the load switching, and case 3 has its bus voltage closer to 1 p.u. than that of case 2 at the steady state. Fig. 7 (d) shows the voltage dip due to the primary side fault occurring at the 150th second, where case 3 has a smaller voltage dip than case 2 because its STATCOM has a higher residual capacity. Without a STATCOM, case 1 has a largest voltage dip.

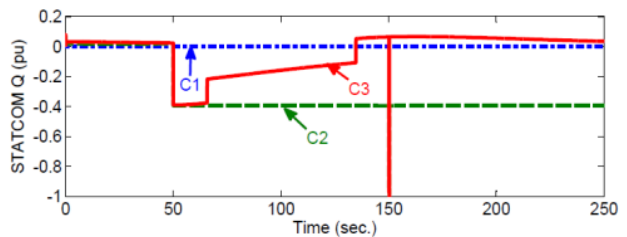

(a)

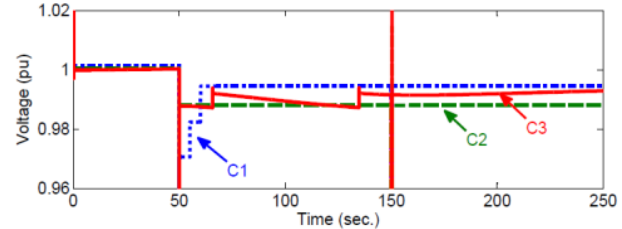

(c)

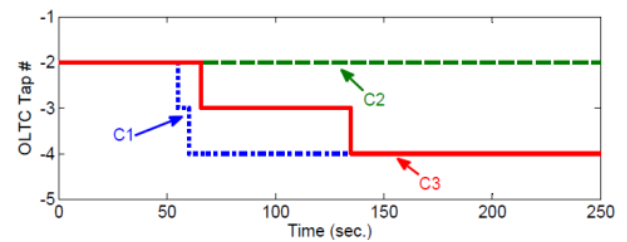

(b)

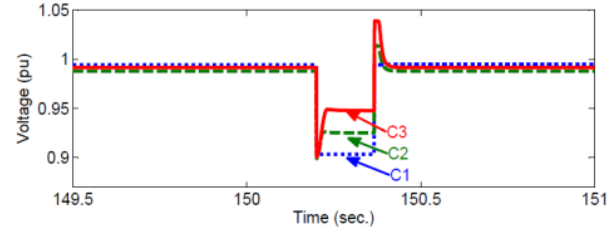

(d)

Fig. 7. Simulation results for scenario 1: (a) STATCOM output, (b) OLTC tap position, (c) secondary bus voltage, and (d) the detail bus voltage around the primary side fault. 


\subsection{Scenario 2: A load variation at $161 \mathrm{kV}$ side}

Fig. 8 shows the simulation results for scenario 2. Similar to the performance in scenario 1 , the proposed controller can gradually decrease the STATCOM output, and the basic controller keeps the STATCOM compensation capacity constant. Fig. 8 (b) shows that the switching-on of load P1 results in only one OLTC tap moving for both case 1 and case 3, with case 3 has a longer time distance between the load switching and the tap moving than that of case 1 which is about 5 seconds. The OLTC of case 2 is inactive to the load P1 switching. In Fig. 8 (c), with a STATCOM, both case 2 and case 3 have a better secondary bus voltage profile than case 1 at the time instant after the load switching. The comparison of Fig. 8 (c) and 7(c) shows that the switching of primary side load P1 has a smaller affect on secondary bus voltage than that of secondary side load S1. Fig. 8 (d) shows the variation of primary side voltage due to the switching of load P1. Because the deviation of primary side voltage from 1 p.u. is inside the \pm 0.04 dead zone, the proposed scheme does not provide any compensation for the primary voltage deviation.

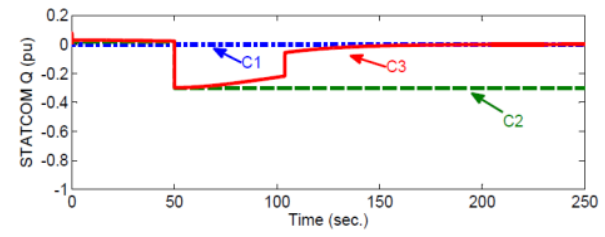

(a)

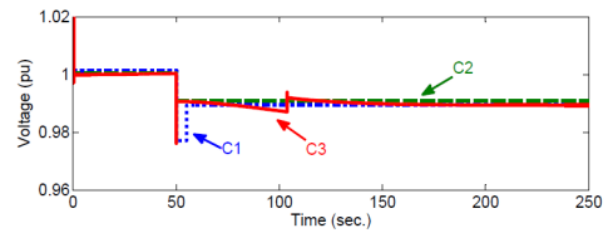

(c)

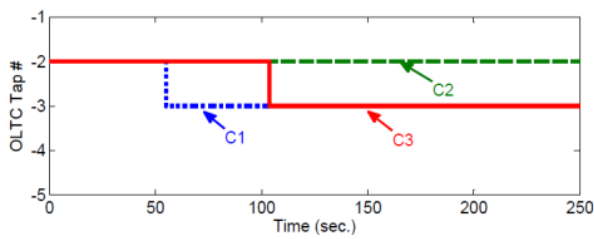

(b)

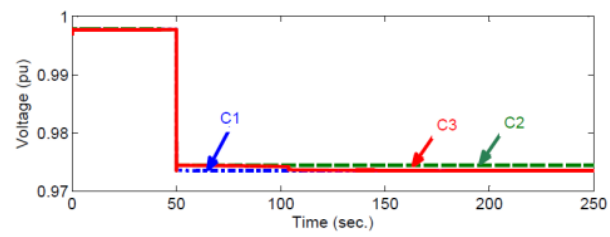

(d)

Fig. 8. Simulation results for scenario 2: (a) STATCOM output, (b) OLTC tap position, (c) secondary bus voltage, and (d) primary bus voltage.

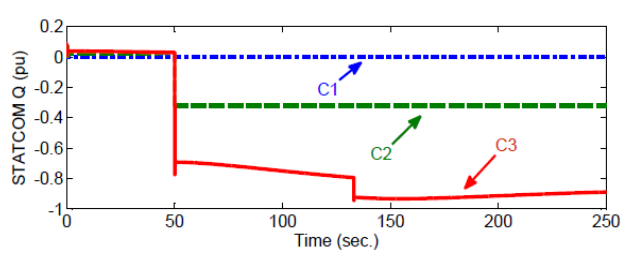

(a)

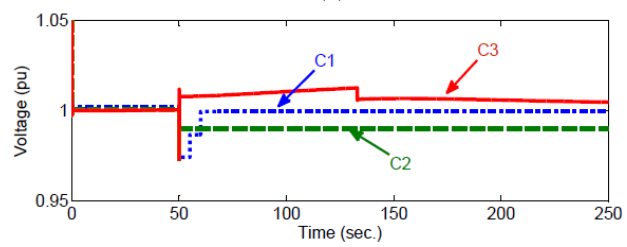

(c)

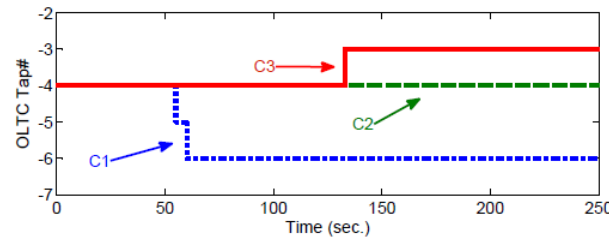

(b)

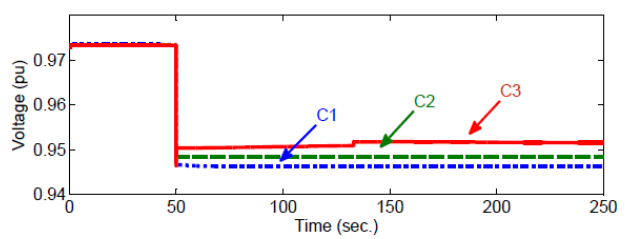

(d)

Fig. 9. Simulation results for scenario 3: (a) STATCOM output, (b) OLTC tap position, (c) secondary bus voltage, and (d) primary bus voltage.

\subsection{Scenario 3: A transmission line tripping at $161 \mathrm{kV}$ side}

Fig. 9 shows the simulation results for scenario 3. Unlike to the performance in scenarios 1 and 2, the proposed controller continuously provides a high STATCOM output for the transmission line tripping, and the basic controller outputs a lower STATCOM compensation capacity. The high STATCOM output from the proposed controller is due to the deviation of primary side voltage from 1 p.u., as shown in Fig 9 (c), is outside the \pm 0.04 dead zone to active the feedback effectiveness of primary side voltage on 
STATCOM $V_{\text {ref. }}$ Fig. 9 (b) shows that the tripping of an upstream transmission line results in only one OLTC tap moving for case 3, and no any tap moving for case 2. In Fig. 9 (c), at the time instant after the load switching, both case 2 and case 3 have a better secondary bus voltage profile than case 1, but at the steady state, the secondary bus voltage profiles of case 1 and case 3 are closer to 1 p.u. than case 2 . Because the proposed controller continuously provides a high STATCOM output, case 3 has better primary side voltage compensation than the basic controller.

\section{Conclusions}

In this paper, a novel STATCOM control scheme for the coordination with OLTC on voltage regulation is proposed and compared with the basic control scheme. The following conclusions are obtained:

1. Without a STATCOM, the low speed OLTC can not provide immediate voltage regulation; there is a high possibility of a poor power quality phenomenon will happen when a large capacity transient occurs.

2. With the basic controller, the coordination between STATCOM and OLTC is poor, and the high speed STATCOM may inactivate the OLTC in many scenarios. Hence, a STATCOM with the basic controller will result in large operating losses and can not provide sufficient reactive power compensation for a transient demand. However, the basic controller results in the least number of OLTC tap changes.

3. The proposed control scheme has less STATCOM losses and number of OLTC tap changes, and can reserve higher capacity for high capacity transients than the basic control scheme. With the feedback of primary voltage, the proposed controller can continuously provide compensation reactive power for long-term primary side transients.

4. The simulation results show that the proposed control scheme can achieve the goal of STATCOM and OLTC coordination.

\section{Acknowledgements}

This work was supported by the National Science Council, Taiwan, ROC, under grant NSC 100-3113P-194-002.

\section{References}

[1] Son KM, Moon KS, Lee SK, Park JK. Coordination of an SVC with a ULTC reserving compensation margin for emergency control. Transactions on Power Delivery, 2000; 15(4):1193-1198.

[2] Radha KRS, Rafi V, Subrahmanyam J, Mazhar UHS. A novel on coordinated voltage control scheme for seigbased wind park utilizing substation statcom and ultc transformer. Global Journal of Researches in Engineering Electrical and Electronics Engineering, 2012; 12(5):1-6.

[3] Fujii T, Chisyaki H, Teramoto H, Sato T, Matsushita Y, Shinki Y, Funahashi S, Morishima N. Coordinated voltage control and continuous operation of the 80 MVA STATCOM under commercial operation. In: Proc. of Power Conversion Conference, 2007:969-974.

[4] El Moursi MS, Bak-Jensen B, Abdel-Rahman MH. Coordinated voltage control scheme for SEIG-based wind park utilizing substation STATCOM and ULTC transformer. IEEE Transactions on Sustainable Energy, 2011; 2(3):246-255.

[5] Khederzadeh M. Coordination control of STATCOM and ULTC of power transformers. In: Proc. of 42nd International Universities Power Engineering Conference, 2007:613-618.

[6] Paserba JJ, Leonard DJ, Miller NW, Naumann ST, Lauby MG, Sener FP. Coordination of a distribution level continuously controlled compensation device with existing substation equipment for long term var management. IEEE Transactions on Power Delivery, 1994; 9(2):1034-1040.

[7] Kim GW, Lee KY. Coordination control of ULTC transformer and STATCOM based on an artificial neural network. IEEE Transactions on Power Delivery, 2005; 20(2):580-586. 